\title{
RESEÑAS
}

\section{Ojeda Escalante, Roberto y Herrera Villagra, Alejandro. Yuyay Taqe. Los incas en su tiempo y en el nuestro.}

Cusco: Universidad Andina del Cusco, 2019, 403 pp.

Cusco se caracteriza por poseer una vasta historia, desde el precerámico hasta nuestros días; en ese entender, son escasos los textos que reúnen tan considerable información en un solo ejemplar como en Yuyay Taqe. Los incas en su tiempo y en el nuestro, una compilación de trabajos científicos efectuado por investigadores internacionales, nacionales y locales, quienes procuran comprender a los actores de la historia desde tiempos pasados y su influencia hasta la actualidad, a partir de sus respectivas disciplinas.

El texto fue publicado el 2019 y se halla organizado en tres partes, las cuales fueron adaptadas a la división espacial inca, es decir, el sistema de ceques (Qollana, los principales; Payan, los parientes cercanos; y Kayau, los parientes lejanos).

Ahora bien, Qollana (primera parte), presenta la figura del inca desde múltiples temáticas a través de los tiempos. Jan Szeminki refiere que son diversas las actitudes que los investigadores optan con respecto a la posibilidad de esccribir la historia de los incas, resultando para unos poco posible porque no hay testimonios escritos, mientras que otros afirman que no tuvieron historia; mas otro tanto refiere que los testimonios deben ser los más cercanos a los acontecimientos que investiga el historiador. En efecto, instrumentos como el khipu y la quillqa fueron objetos en los que se guardaron información sobre el pasado del
Tawantinsuyu. Por el autor se sabe que la función de la tradición consistió en informar cómo la misión llegaba al gobernante del momento, desde Manqu Qhapaq Inqa hasta después de José Gabriel Thupa Amaro.

Juan Ossio Acuña basa su artículo en las informaciones de Felipe Guaman Poma de Ayala [1615], quien equipara la imagen del inca con la del rey de España, colocándolo al centro de otros cuatro gobernantes subalternos, de manera que el «monarca» es asimilado a un principio metafísico sustentador del orden, atribuyéndole una categoría divina. Del mismo modo, como mediador de opuestos complementarios (derecha-izquierda, Hanan-Hurin, Chinchaysuyu-Antisuyu, Collasuyu-Contisu$\mathrm{yu}$ ), toma una posición en torno a la naturaleza, denominándolo Intipchurin (hijo del Sol).

Alejandro Herrera Villagra desarrolla su artículo basado en La instrucción al licenciado Lope de García (1570), un documento formulado por Titu Cusi Yupanqui y que fue empleado como medio de comunicación entre el Sapai Inga y el rey de España, Felipe II. Esta investigación es importante desde dos puntos de vista; el primero, muestra el sistema de comunicación aprendido y adoptado por un indígena para establecer relaciones diplomáticas con la corona española; segundo, las circunstancias del momento obligan al indígena a aprender una cultura nueva, con el objetivo de establecer

(C) Los autores. Este artículo es publicado por ISHRA, Revista del Instituto Seminario de Historia Rural Andina de la Facultad de Ciencias Sociales de la Universidad Nacional Mayor de San Marcos. Este es un artículo de acceso abierto, distribuido bajo los términos de la licencia Creative Commons Atribución 4.0 Internacional (CC BY 4.0) [https://creativecommons.org/licenses/by/4.0/deed.es] que permite el uso, distribución y reproducción en cualquier medio, siempre que la obra original sea debidamente citada de su fuente original. 
comunicación con los dominadores, expresando su descontento.

Carlos Zegarra Moretti analiza la definición del término inca a partir del Diccionario Kkechuwa-Español, publicado en 1944 y redactado por el sacerdote cusqueño Jorge A. Lira, considerado uno de los representantes de la literatura local, además de quechuólogo y antropólogo. La imagen del inca en el diccionario aborda aspectos de origen mítico, social, religioso, y de extensión temporal. El término inca adopta otras denominaciones como $\mathrm{em}$ perador, monarca, soberano, etc. Asimismo, manifiesta que el gobierno en el Tawantinsuyu se desarrolló de manera comunitaria, cuya población se hallaba unida por vínculos comunes, poseyendo derechos y deberes. La imagen del inca es remontada al origen mítico de los hermanos Ayar, equiparándolos al origen cristiano (Noé y sus tres hijos).

Por otro lado, Payan (segunda parte) agrupa artículos sobre la sociedad, presentando algunos aspectos sobre las manifestaciones culturales de la colectividad inca. Iván Ccallo Mamani estudia la iconografía de las cerámicas Wari, Qotakalli, Lucre, Killke e Inka, procedentes de los sitios arqueológicos de Choquepukio y Minaspata. No es novedad manifestar que en Cusco existieron diferentes grupos étnicos que se hallaban bajo un mismo control estatal expansivo, cuya clara evidencia es la repercusión iconográfica de la cerámica Killke, Lucre y Wari en los diferentes grupos étnicos como los ayarmaka, antis, chillke, masca, etc. Finalmente, en el estilo Inca Clásico, el diseño Lucre llega a su máxima expresión consolidándose como un icono estatal representativo del poder inca.

Jesús Washington Rozas Álvarez examina el significado que encierra el traslado de las piedras cansadas, piezas fundamentales en la construcción de diferentes edificaciones, sobre todo de aquellas piedras que, por razones circunstanciales, no llegaron a su destino, expresándolo en llanto con lágrimas de sangre (que significa el no haber cumplido el objetivo planificado y prometido) para ser parte integrante de la ciudad sagrada o de alguna otra edificación. Cabe señalar que cada piedra era considerada una waka; el traslado se equiparó a una práctica agrícola denominada wacho, que significa surco, el cual que consistía en efectuar una tarea de inicio a fin.

Roberto Ojeda Escalante y Claudia Palomino Valdivia describen una de las técnicas andinas prehispánicas de producción agrícola más avanzadas como las qolqas, sistema que en tiempos de Covid-19 serían una alternativapara la alimentación, evitando la hambruna y desplazamientos de la población hacia sus lugares de origen. Cabe señalar que existieron dos clases de qolqas, una del Estado y la otra del pueblo, la primera que proveía a la población de mitayos, y la segunda a los ayllus (qolqas denominados sapsis). El proceso o técnica de conservación de los alimentos se efectuaba mediante el proceso del qachay, que consistía en la deshidratación de ciertos alimentos, cuyo proceso llegaba más allá porque se elaboraban comidas que podían durar semanas y hasta meses; dicha comida se denominaba qoqaw o fiambre.

Anael Pilares Valdivia trata un tema sobre salubridad y patrimonio. Manifiesta que en el Cusco de antaño se daba suma importancia simbólica a los ríos (Saphi, Tullumayo y Huatanay). Saphi fue un afluente hídrico que formó parte significativa de la cosmovisión incaica, además de ser elemento ordenador limítrofe, es decir, frontera natural entre el centro de la ciudad sagrada y las zonas de andenería; asimismo, en el periodo incaico cumplió un valor simbólico. En el virreinato fue una vía de movilidad. En la actualidad, Saphi se conoce más por la calle, fracción de área en el que se construyó el hotel Sheraton. Cusco, al ser registrado por UNESCO como Patrimonio Histórico de la Humanidad, debe custodiar todo patrimonio cumpliendo las normas elementales; de lo contrario perdería el referido título.

El siguiente bloque, Kayau (tercera parte) concentra artículos que relacionan al Estado 
inca y las poblaciones étnicas sometidas, además del mito del ñak'aq en la memoria colectiva. Antoinette Molinié fundamenta su artículo en datos etnográficos sobre un rito contemporáneo andino: la batalla ritual del Tinku, guerra ritual en donde se enfrentan las mitades de sociedades dualistas; además, propone una dimensión interesante de dos tipos de rituales denominados Tinku y Capac Hocha, distinguiendo la depredación y el sacrificio. La primer consiste en la transformación de la etnia vencida, a través de la depredación de órganos, mientras que la segunda implica un culto practicado por sacerdotes, es decir, la operación de sacrificio requiere de una divinidad.

Edgard Villafuerte Acuña y Angela María Concha detallan el complicado proceso de encajamiento activo y reordenamiento de las poblaciones étnicas de Cocharcas bajo el régimen virreinal, quienes anteriormente a dicho periodo, mantenían constantes luchas étnico-curacales entre chancas, incas y mitimaes por la hegemonía del poder; los últimos transfiguraron los aspectos sociales, políticos y religiosos del área ocupada. El análisis de las fuentes de archivo tanto de Cusco como del Santuario de Cocharcas permite comprender la evolución histórica de la provincia de Andahuaylas «la Grande», a partir de sus cuatro repartimientos del norte.

El artículo de Juan Cincunegui de la Vega gira en torno al mito del naq'ak, imaginario social de las poblaciones andinas contemporáneas.
Su información etnográfica es trabajada a partir de la Relación de las fabulas y ritos de los Incas (1574) de Cristóbal de Molina, el cusqueño, y la Historia Bethlemítica (1723) de Fray Joseph García de la Concepción. Igualmente, Hanny Fernández Coronel investiga acerca del ñak'aq en el contexto actual de conflictos socioeconómicos vinculados con la minería en la jurisdicción de Calca, que involucrarían a empresas privadas y al Estado peruano, en cuya circunstancia aparece en el imaginario del poblador calqueño el personaje ñak'aq, quien ataca a su víctima para extraerle la grasa.

Finalmente, a manera de apéndice del texto se aborda el tema de la educación en tiempos de pandemia. La educación virtual se convirtió en un reto para la comunidad educaciona, pues el proceso de aprendizaje debía darse en un conexto de confinamiento, práctica contraria a lo que Jaime Aráoz Chacón da a conocer a través de una práctica educativa que involucra a diversos actores sociales (la comunidad educativa del colegio Alejandro Velasco Astete, los alcaldes de las municipalidades de San Jerónimo y San Sebastián, las comunidades originarias de la ruta de los Ayar, los Ministerios de Cultura y de Educación, entre otros) que, a partir de experiencias y vivencias permiten valorar la cultura viva del Tawantinsuyu, además de fortalecer nuestra identidad cultural al desarrollar la ceremonia comunal denominada Ritual del Wanakawri, que permite experimentar un encuentro con la pachamama.

\section{Lisbeth Judit Cusicuna Vilca}

https://orcid.org/0000-0003-2010-9516 vilcalisbeth3@gmail.com

Centro Cusqueño de Investigaciones Históricas Enfoques

Publicado online: 10/08/2021 